\title{
Reliability and validity of the Female Sexual Function Index administered via telephone in Brazilian women
}

\author{
Raquel Eleine Wolpe ${ }^{(1)}$, Priscilla Geraldine Wittkopf ${ }^{(1)}$, Matheus Pereira Peres Martins ${ }^{(1)}$, Géssica Maria Moreira ${ }^{(1)}$, \\ Suellen Bitencourt Rosa ${ }^{(1)}$, Fabiana Flores Sperandio(1)
}

\begin{abstract}
Background: Women's sexuality is influenced by anatomical, physiological, psychological and cultural factors. It is likely that questionnaires comprehensively evaluate women's sexual aspects. The Female Sexual Function Index (FSFI) is considered a gold standard instrument to assess female sexual function. The validation of the administration of this questionnaire via telephone has a high research and clinical importance. Objectives: The aim of this study was to evaluate the validity and reliability of the FSFI administered via telephone in Brazilian women. Methods: 51 women answered the FSFI by telephone and paper with an interval of one week between both administrations. After two weeks of the application via telephone (test), the questionnaire was administered again, also via telephone (retest), to verify the reliability. the Spearman's rank correlation index was used to estimate the relationship between FSFI-phone and FSFI-paper. Intraclass correlation coefficient (ICC) was used to assess the FSFI-phone reliability (test-retest). Results: The Spearman's rank test showed a high correlation between the total scores of the FSFI-phone and FSFI-paper with value of 0.96 . Correlations between the questions and domains were conducted in pairs, which reached levels higher than 0.70 . The ICC values were even higher (ICC> 0.90). Conclusions: These preliminary results, showed that the FSFI questionnaire administered via telephone is a valid, reliable and responsive method that facilitates quality assurance and can potentially reduce human resource costs in data acquisition. The use of FSFI administered via telephone addresses a logistic need for patient and physician, by providing fast and safe information convenient to both patient and practitioner.
\end{abstract}

Keywords: Sexual Dysfunction; Surveys and Questionnaires; Validation Studies; Reproducibility of Results; Telephone.

\section{INTRODUCTION}

Women's sexuality is influenced by anatomical, physiological, psychological and cultural factors ${ }^{(1)}$. Although there are some objective examinations, such as photo plethysmography, Doppler velocimetry, labial temperature and nuclear magnetic resonance, these measures fail to evaluate female's sexual functioning in a comprehensive away (2). Therefore, it is likely that questionnaires should be able to better evaluate all women's sexual aspects.

The Female Sexual Function Index (FSFI) is the most widely used questionnaire in research and clinical practice ${ }^{(3)}$. Developed and validated as a brief self-report measure of female sexual functioning, it is divided in 6 domains: desire, arousal, lubrication, orgasm, satisfaction and pain ${ }^{(4)}$. The FSFI helps not only to identify sexual dysfunction but can specify which domain of the sexual life is more impaired.

The FSFI has been successfully translated and psychometrically validated in approximately 16 languages, including Spanish(5), Turkish ${ }^{(6)}$, Malay(7), Finnish ${ }^{(8)}$, German $^{(9)}$,
Chinese $^{(10)}$, Arabic $^{(11)}$, Japanese ${ }^{(12)}$, Persian $^{(13)}$ Philippines $^{(14),}$ Polish ${ }^{(15)}$, Italian ${ }^{(16)}$, among others. Paper and electronic based versions of the FSFI questionnaire have already been validated $^{(3,17)}$. However, the administration of the questionnaire via telephone is yet to be validated. The use of telephone in health care has played an important role in research and public health practice given its advantages of time, reduced costs, greater geographical accessibility and larger sample sizes ${ }^{(18-21)}$.

The number of mobile phone users in the world is expected to pass the 5 billion mark by 2019 (22). In Brazil, it is estimated that there are 139.1 million people who own mobile phones for personal use, and up until March 2017 there were 41 million active landlines ${ }^{(23,24)}$. Considering the spectrum of Brazilian and worldwide telephony, telephone becomes a convenient and economical interface to accessing health-related information. Administration of the FSFI questionnaire via telephone has added advantages, as it can avoid embracement-related bias when compared to face-to-face interview ${ }^{(25)}$. In addition, when 
compared to electronic and self-administered methods, the questionnaire can be administered more comprehensively as the interviewer, over the telephone, can motivate respondents to answering 'uncomfortable' questions as well as encourage longer responses and clarify items ${ }^{(20)}$. Administration of questionnaires via telephone may also overcome limitations associated with in-person follow-up, including illness, willingness to return for an interview or lack of transportation.

Thus, the aim of this study was to evaluate the preliminary results of the validity and reliability of the FSFI administered via telephone.

\section{METHOD}

\section{Participants}

57 women aged 18 years or above were recruited from the university staff and students via convenience sampling. Participants were excluded if they I) failed to respond to a phase of the process; II) did not answer all questions and III) did not respond within data collection time.

\section{Measures}

To characterize the sample, a socio-demographic questionnaire was used with questions regarding age, marital status, educational level and family income.

The FSFI(4) is a specific and multidimensional self-administered tool to evaluate the female sexual function.
The instrument consists of 19 questions, grouped into six domains: desire, arousal, lubrication, orgasm, satisfaction and pain. A score is calculated for each domain, and the sum of scores corresponds to the overall sexual function, which ranges from 2 to 36 points. Scores $\leq 26.55$ has been considered the cut-off point for identifying the risk of female sexual dysfunction ${ }^{(26)}$. The Portuguese version of the instrument validated by Thiel et al. (2008) was used in this study ${ }^{(27)}$.

\section{Procedures}

Volunteers were initially randomised using a sealed envelope procedure and divided into two groups (Figure 1). Both groups answered the questionnaire in paper (self-administered) and through telephone as an interview on separate occasions. An experienced and trained interviewer conducted all interviews. A pilot study was conducted with 11 participants, as no modifications were required, the sample from pilot study was included in the main analysis.

The first group answered the questionnaire via telephone as an interview (FSFI-phone) (test), while the second group answered the questionnaire via paper (FSFI-paper) (self-administered). A one-week interval was given for groups to answer the questionnaire for the second time, switching the application method. 2 weeks after testing, both groups answered again via telephone (retest).

All participants gave written consent and the local institutional ethics committee approved the study.

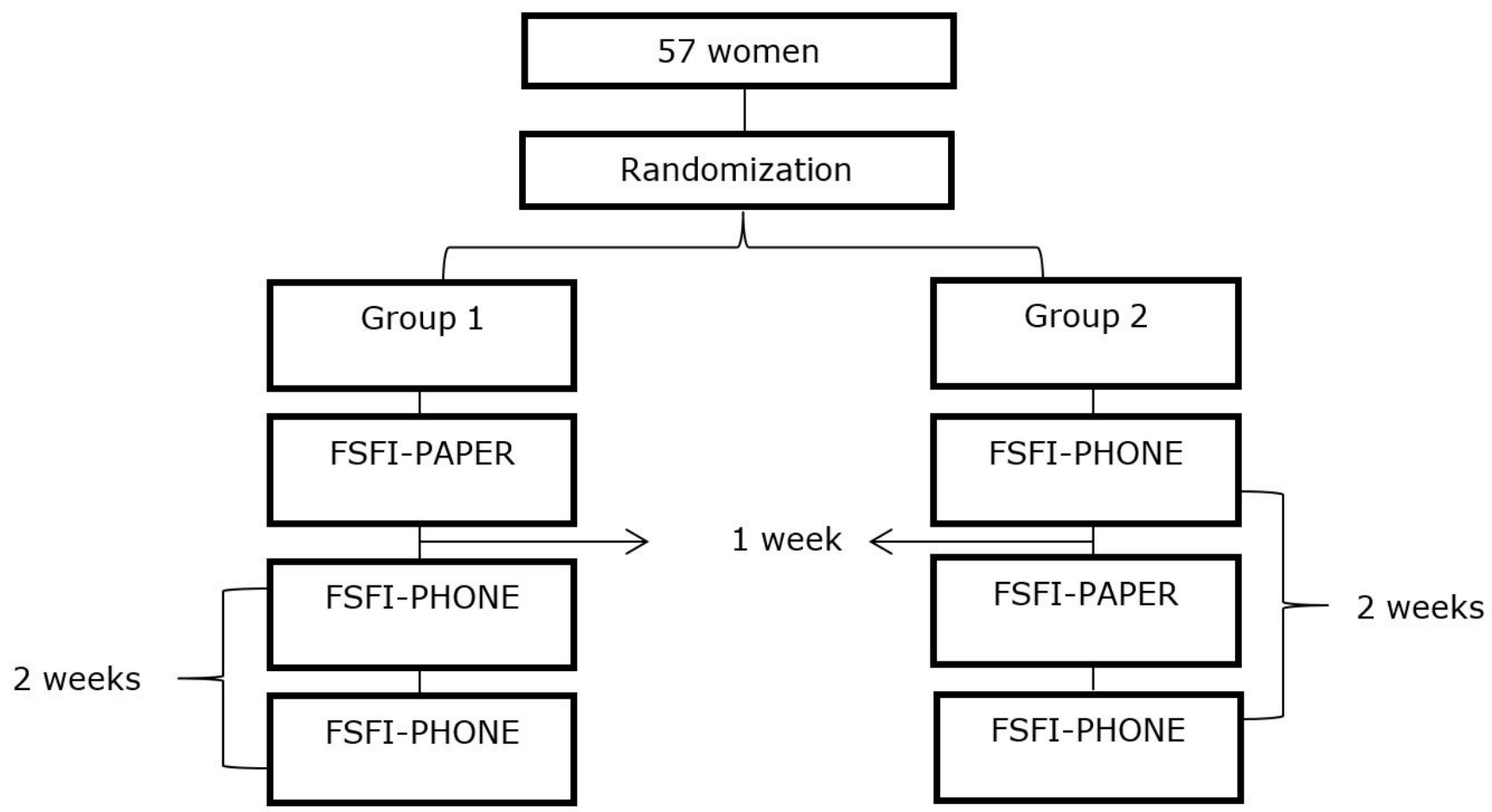

Figure 1. Data collection flowchart. 


\section{Statistical analysis}

Statistical analysis was performed using SPSS - Statistical Package for Social Sciences (version 20.0). Normal distribution was tested with Kolmogorov-Smirnov test. The significance level adopted was $p<0.05$. For each question, domain and total FSFI score, the Spearman rank correlation index was used to estimate the relationship between FSFI-phone and FSFI-paper. Intraclass correlation coefficient (ICC) was used to assess the FSFI-phone Reliability (test-retest).

\section{RESULTS}

Of the 57 primary eligible participants, $6(10.54 \%)$ were excluded because they did not respond to one of the phases of the process, changed telephone number, or responded too late, even after five contact attempts including night time am weekends. The final sample consisted of 51 women with mean age of $30.73 \pm 12.69$ years. Regarding marital status $68.6 \%$ were single, $23.5 \%$ married, $3.9 \%$ widowed,
$2 \%$ divorced and $2 \%$ did not report. Sixty-three percent had incomplete higher education (University/College), 23.5\% complete higher education, $9.8 \%$ post-graduation and $3.7 \%$ did not report. Fifty-one percent had family income less than U\$ $12,692.52$ and $49 \%$ from U\$ $12,692.52$ to U\$ 25,385.16.

The Spearman Rank validity test showed high correlation between total scores of the FSFI-phone and FSFI-paper (0.96). Correlations between questions and domains were performed in a paired form, which reached indexes greater than 0.70 (Table 1).

Reliability assessment revealed high Intraclass Correlation Coefficient values (ICC>0.90) (Table 2).

\section{DISCUSSION}

The present study intended to assess reliability and correlation between results of telephone and paper based methods of administration of the FSFI, which is an important

Table 1. Validity tests results of the Female Sexual Function Index administered via telephone in Brazilian women

\begin{tabular}{|c|c|c|c|c|}
\hline \multicolumn{2}{|c|}{ Variable } & \multirow{2}{*}{$\frac{\text { Paper Mean** }}{2.96 \pm 1.30}$} & \multirow{2}{*}{$\frac{\text { Phone Mean** }}{3.24 \pm 1.46}$} & \multirow{2}{*}{$\frac{\text { Validation test* }}{0.80^{\dagger}}$} \\
\hline Desire & Question 1 & & & \\
\hline & Question 2 & $2.92 \pm 0.98$ & $3.12 \pm 1.03$ & $0.80+$ \\
\hline \multirow[t]{4}{*}{ Arousal } & Question 3 & $3.12 \pm 2.09$ & $3.25 \pm 2.05$ & $0.83^{\dagger}$ \\
\hline & Question 4 & $2.80 \pm 1.80$ & $2.90 \pm 1.80$ & $0.91+$ \\
\hline & Question 5 & $2.86 \pm 1.95$ & $2.80 \pm 1.81$ & $0.95^{+}$ \\
\hline & Question 6 & $3.22 \pm 2.11$ & $3.24 \pm 2.06$ & $0.86+$ \\
\hline \multirow[t]{4}{*}{ Lubrication } & Question 7 & $3.29 \pm 2.15$ & $3.25 \pm 2.04$ & $0.91+$ \\
\hline & Question 8 & $3.18 \pm 2.14$ & $3.18 \pm 2.07$ & $0.92+$ \\
\hline & Question 9 & $3.29 \pm 2.13$ & $3.25 \pm 2.03$ & $0.89+$ \\
\hline & Question 10 & $3.27 \pm 2.15$ & $3.31 \pm 2.06$ & $0.97+$ \\
\hline \multirow[t]{3}{*}{ Orgasm } & Question 11 & $2.80 \pm 1.99$ & $2.92 \pm 1.96$ & $0.84{ }^{\dagger}$ \\
\hline & Question 12 & $2.88 \pm 2.04$ & $2.94 \pm 1.96$ & $0.88^{+}$ \\
\hline & Question 13 & $2.97 \pm 1.96$ & $2.88 \pm 1.98$ & $0.84+$ \\
\hline \multirow[t]{3}{*}{ Satisfaction } & Question 14 & $3.22 \pm 2.16$ & $3.29 \pm 2.07$ & $0.90+$ \\
\hline & Question 15 & $3.57 \pm 1.84$ & $3.61 \pm 1.74$ & $0.94+$ \\
\hline & Question 16 & $3.49 \pm 1.70$ & $3.53 \pm 1.60$ & $0.74+$ \\
\hline \multirow[t]{3}{*}{ Pain } & Question 17 & $3.24 \pm 2.13$ & $3.29 \pm 2.03$ & $0.94+$ \\
\hline & Question 18 & $3.37 \pm 2.13$ & $3.45 \pm 2.06$ & $0.93+$ \\
\hline & Question 19 & $3.25 \pm 2.09$ & $3.33 \pm 2.04$ & $0.94+$ \\
\hline \multirow[t]{6}{*}{ Domains } & Desire & $3.58 \pm 1.26$ & $3.81 \pm 1.41$ & $0.81+$ \\
\hline & Arousal & $3.60 \pm 2.30$ & $3.66 \pm 2.40$ & $0.91+$ \\
\hline & Lubrication & $3.91 \pm 2.51$ & $3.90 \pm 2.40$ & $0.97+$ \\
\hline & Orgasm & $3.35 \pm 2.31$ & $3.50 \pm 2.30$ & $0.92+$ \\
\hline & Satisfaction & $4.11 \pm 2.09$ & $4.17 \pm 1.99$ & $0.94{ }^{\dagger}$ \\
\hline & Pain & $3.95 \pm 2.50$ & $4.03 \pm 2.42$ & $0.97+$ \\
\hline Total Score & & $22.50 \pm 11.83$ & $23.07 \pm 11.79$ & $0.96+$ \\
\hline
\end{tabular}

Note: * Spearman Rank (rho). ${ }^{* *}$ Mean \pm Standard deviation. ${ }^{\dagger} \mathrm{p}<0.001$. 
Table 2. Reliability tests results of the Female Sexual Function Index administered via telephone in Brazilian women

\begin{tabular}{|c|c|c|c|c|}
\hline \multicolumn{2}{|c|}{ Variable } & \multirow{2}{*}{$\frac{\text { Test Mean** }}{3.24 \pm 1.46}$} & \multirow{2}{*}{$\frac{\text { Retest Mean** }}{3.20 \pm 1.43}$} & \multirow{2}{*}{$\frac{\text { Reliability test* }}{0.94 \dagger}$} \\
\hline Desire & Question 1 & & & \\
\hline & Question 2 & $3.12 \pm 1.03$ & $3.08 \pm 1.03$ & $0.95+$ \\
\hline \multirow[t]{4}{*}{ Arousal } & Question 3 & $3.25 \pm 2.05$ & $3.18 \pm 2.03$ & $0.95+$ \\
\hline & Question 4 & $2.90 \pm 1.80$ & $2.84 \pm 1.80$ & $0.96+$ \\
\hline & Question 5 & $2.80 \pm 1.81$ & $2.82 \pm 1.85$ & $0.98^{+}$ \\
\hline & Question 6 & $3.24 \pm 2.06$ & $3.12 \pm 2.07$ & $0.97+$ \\
\hline \multirow[t]{4}{*}{ Lubrication } & Question 7 & $3.25 \pm 2.04$ & $3.29 \pm 2.13$ & $0.97+$ \\
\hline & Question 8 & $3.18 \pm 2.07$ & $3.20 \pm 2.10$ & $0.96+$ \\
\hline & Question 9 & $3.25 \pm 2.03$ & $3.25 \pm 2.10$ & $0.99+$ \\
\hline & Question 10 & $3.31 \pm 2.06$ & $3.25 \pm 2.14$ & $0.99+$ \\
\hline \multirow[t]{3}{*}{ Orgasm } & Question 11 & $2.92 \pm 1.96$ & $2.75 \pm 1.96$ & $0.95+$ \\
\hline & Question 12 & $2.94 \pm 1.96$ & $2.80 \pm 1.97$ & $0.97+$ \\
\hline & Question 13 & $2.88 \pm 1.98$ & $2.69 \pm 1.97$ & $0.95+$ \\
\hline \multirow[t]{3}{*}{ Satisfaction } & Question 14 & $3.29 \pm 2.07$ & $3.27 \pm 2.14$ & $0.98+$ \\
\hline & Question 15 & $3.61 \pm 1.74$ & $3.57 \pm 1.78$ & $0.97+$ \\
\hline & Question 16 & $3.53 \pm 1.60$ & $3.31 \pm 1.68$ & $0.90+$ \\
\hline \multirow[t]{3}{*}{ Pain } & Question 17 & $3.29 \pm 2.03$ & $3.22 \pm 2.07$ & $0.97+$ \\
\hline & Question 18 & $3.45 \pm 2.06$ & $3.37 \pm 2.13$ & $0.99+$ \\
\hline & Question 19 & $3.33 \pm 2.04$ & $3.24 \pm 2.07$ & $0.98^{+}$ \\
\hline \multirow[t]{6}{*}{ Domains } & Desire & $3.81 \pm 1.41$ & $3.76 \pm 1.40$ & $0.97^{+}$ \\
\hline & Arousal & $3.66 \pm 2.40$ & $3.59 \pm 2.25$ & $0.97+$ \\
\hline & Lubrication & $3.90 \pm 2.40$ & $3.90 \pm 2.48$ & $0.98+$ \\
\hline & Orgasm & $3.50 \pm 2.30$ & $3.29 \pm 2.30$ & $0.97+$ \\
\hline & Satisfaction & $4.17 \pm 1.99$ & $4.06 \pm 2.05$ & $0.98+$ \\
\hline & Pain & $4.03 \pm 2.42$ & $3.93 \pm 2.48$ & $0.99+$ \\
\hline Total Score & & $23.07 \pm 11.79$ & $22.54 \pm 11.85$ & $0.98+$ \\
\hline
\end{tabular}

Note: ${ }^{*}$ Intraclass correlation coefficient (ICC). ${ }^{* *}$ Mean \pm standard deviation. ${ }^{\dagger} p<0.001$

instrument in research and clinical practice. Our results showed a good correlation between both methods of administration and indicates that the measurements are stable in a temporal context.

Other investigators have validated telephone-administered questionnaires in various field of health care ${ }^{(18,25,28)}$, including two specific to women's health area ${ }^{(29)}$. Our study adds to the body of resources that are needed to improve scientific research and follow up treatments, specific to women's sexual function.

Correlation values among questions, domains and total scores of the FSFI-phone and FSFI-paper were high, indicating that the FSFI administered via telephone is valid. It is important to note that question 16 , related to satisfaction domain showed a moderate correlation 0.74 . It suggests that this question should be carefully evaluated when using the questionnaire. Sexual satisfaction consists of a general conclusion about how much sexual life is pleasant, with a particular judgment of pleasure generated by sexual behaviour. As sexual satisfaction is a subjective construct based on a selfanalysis, which is constantly changing, time difference between evaluations could have interfered in this result ${ }^{(30)}$.

Regarding the reliability test, values showed good agreement between the two time periods of administration (ranging from 0.90 to 0.99 ). These values corroborate results of the original validation study ${ }^{(4)}$ which showed values from 0.79 to 0.88 . Question 16 showed the smallest correlation coefficient (0.9). Although it is still classified as excellent, taken together with the validity results, it suggests that responses to this question can sow variability over time.

Our survey had several limitations. First, there was no sample size calculation, therefore, we suggest that further research is needed with a proper sample size calculation, including the percentage of expected dropouts. The second 
limitation was the long time required for data collection ( 3 weeks). The third limitation of this study may include a lack of reliable answers on the telephone-administered version because of subjects embarrassment. Although, this reporting bias is also possible on the self-administered written version. Finally, there are limits to results generalisability due to high level of education and sociodemographic and economic conditions of the sample.

\section{CONCLUSION}

In conclusion, these preliminary results showed that the FSFI administered via telephone is a reliable, valid, and responsive method that facilitates quality assurance and can potentially reduce human resource costs in data collection. A telephone-based method also provides opportunities for remote data collection without the need for a clinic visit, for verification of the identity of the person completing the questionnaire, and provides the exact time, date of questionnaire completion. The acquisition of quantitative data can be time consuming and a significant deterrent to routine use of quantitative information in clinical practice. The use of FSFI administered via telephone addresses a logistic need for patient and physician, by providing fast and safe information convenient to both patient and practitioner.

\section{AUTHOR'S CONTRIBUTIONS}

REW, PGW and FFS designed the research. REW and PGW performed statistical analysis. REW, PGW, MPPM, SBR and GMM interpreted the data and wrote the manuscript. REW, PGW, MPPM, SBR, GMM and FFS critically revised the manuscript. All the authors read and approved the final manuscript.

\section{CONFLICT OF INTEREST}

The authors declare that there was no conflict of interest.

\section{REFERENCES}

[1] Masters WH and Johnson VE. Human sexual response. Great Britain: Little Brown, 1966.

[2] Rosen RC. Assessment of female sexual dysfunction: review of validated methods. Fertil Steril. 2002; 77(Suppl 4):S89-93.

[3] Crisp CC, Fellner AN, Pauls RN. Validation of the Female Sexual Function Index (FSFI) for web-based administration. Int Urogynecol J. 2014; 26(Suppl 2):219-22.

[4] Rosen R, Brown C, Heiman J, Leiblum S, Meston C, Shabsigh R, et al. The Female Sexual Function Index (FSFI): a multidimensional self-report instrument for the assessment of female sexual function. J Sex Marital Ther. 2000; 26(Suppl 2):191-208.

[5] Blumel J, Binfa LE, Cataldo PA, Carrasco AV, Izaguirre HL, Sarrá SC. Indice de Función Sexual Femenina: un test para evaluar la sexualidad de la mujer. Rev Chil Obstet Ginecol. 2004; 69(Suppl 2):118-25.

[6] Oksuz E, Malhan S. Prevalence and risk factors for female sexual dysfunction in Turkish women. J Urol. 2006; 175(Suppl 2):654-58.

[7] Sidi H, Abdullah N, Puteh SE, Midin M. The Female Sexual Function Index (FSFI): validation of the Malay version. J Sex Med. 2007; 4(Suppl 6):1642-54

[8] Witting K, Santtila P, Jern P, Varjonen M, Wager I, Höglund M, et al. Evaluation of the female sexual function index in a population based sample from Finland. Arch Sex Behav. 2008; 37(Suppl 6):912-24.
[9] Kriston L, Günzler C, Rohde A, Berner MM. Is one question enough to detect female sexual dysfunctions? A diagnostic accuracy study in 6,194 women. J Sex Med. 2010; 7(Suppl 5):1831-41.

[10] Sun X, Li C, Jin L, Fan Y, Wang D. Development and validation of Chinese version of female sexual function index in a Chinese population-a pilot study. J Sex Med. 2011; 8(Suppl 4):1101-11.

[11] Anis TH, Gheit SA, Saied HS, Al kherbash AS. Arabic translation of Female Sexual Function Index and validation in an Egyptian population. J Sex Med. 2011; 8(Suppl 12):3370-8.

[12] Takahashi M, Inokuchi T, Watanabe C, Saito T, Kai I. The Female Sexual Function Index (FSFI): development of a Japanese version. J Sex Med. 2011; 8(Suppl 8):2246-54.

[13] Ghassamia M, Asghari A, Shaeiri MR, Safarinejad MR. Validation of psychometric properties of the Persian version of the Female Sexual Function Index. Urol J. 2013; 10(Suppl 2):878-85.

[14] Rillon-Tabil N, Malong CLP, Vicera JJB, Gomez HS. Translation and Validity of the Female Sexual Function Index Filipino Version (FSFI-Fil). Phil J Intern Med. 2013; 51(Suppl 4):1-11.

[15] Nowosielski K, Wróbel B, Sioma-Markowska U, Poręba R. Development and validation of the Polish version of the Female Sexual Function Index in the Polish population of females. J Sex Med. 2013; 10(Suppl 2):386-95.

[16] Filocamo MT, Serati M, Li Marzi V, Costantini E, Milanesi M, Pietropaolo A, et al. The Female Sexual Function Index (FSFI): linguistic validation of the Italian version. J Sex Med. 2014; 11(Suppl 2):447-53.

[17] Latorre GF, Bilck PA, Cardoso FL, Sperandio FF. Confiability and reliability of an on-line version of the Female Sexual Function Index by test-retest. Rev Bras Ginecol Obstet. 2013; 35(Suppl 10):469-74.

[18] Fine TH, Contractor AA, Tamburrino M, Elhai JD, Prescott MR, Cohen $\mathrm{GH}$, et al. Validation of the telephone-administered PHQ-9 against the in-person administered SCID-I major depression module. J Affect Disord. 2013; 150(Suppl 3):1001-7.

[19] Tuzcu A, Bahar Z, Gozum S. Effects of interventions based on health behavior models on breast cancer screening behaviors of migrant women in Turkey. Cancer Nurs. 2016; 39(Suppl 2):E40-50.

[20] Bowling A. Mode of questionnaire administration can have serious effects on data quality. J Public Health (Oxf). 2005; 27(Suppl 3):281-91.

[21] Ashing K, Rosales M. A telephonic-based trial to reduce depressive symptoms among Latina breast cancer survivors. Psychooncology. 2014; 23(Suppl 5):507-15.

[22] Statista: The Statistics Portal. Number of mobile phone users worldwide from 2013 to 2019 (in billions). Retrieved October 20, 2017, from http:// www.statista.com/statistics/274774/forecast-of-mobile-phone-usersworldwide/.

[23] National Telecommunications Agency (ANATEL). (2017). Services Mobile Data and Satellite. Brasilia: ANATEL.

[24] Brazilian Institute of Geography and Statistics (IBGE). (2017). States: Santa Catarina, Profile 2013. Brasilia: IBGE.

[25] Bokshan SL, Godzik J, Dalton J, Jaffe J, Lenke LG, Kelly MP. Reliability of the revised Scoliosis Research Society-22 and Oswestry Disability Index (ODI) questionnaires in adult spinal deformity when administered by telephone. Spine J. 2016; 16(Suppl 9):1042-6.

[26] Wiegel M, Meston C, Rosen R. The Female Sexual Function Index (FSFI): cross-validation and development of clinical cutoff scores. J Sex Marital Ther. 2005; 31(Suppl 1):1-20.

[27] Thiel RR, Dambros M, Palma PC, Thiel M, Riccetto CLZ, Ramos MF. Translation into Portuguese, cross-national adaptation and validation of the Female Sexual Function Index. Rev Bras Ginecol Obstet. 2008; 30(Suppl 10):504-10.

[28] Fonseca AM, Meinberg MF, Lucas DV, Monteiro MV, Figueiredo EM, Fonseca $L$, et al. Cultural adaptation and validation of the Wexner scale in patients with anal incontinence in a Brazilian population. Int Urogynecol J. 2016; 27(Suppl 6):959-63. 
[29] Geller EJ, Barbee ER, Wu JM, Loomis MJ, Visco AG. Validation of telephone administration of 2 condition-specific quality-of-life questionnaires. Am J Obstet Gynecol. 2007; 197(Suppl 6):632.e1-4.
[30] Gonzáles Al, Sties SW, Wittkopf PG, Mara LS, Ulbrich AZ, Cardoso FL, et al. Validation of the International Index of Erectile Function (IIFE) for Use in Brazil. Arq Bras Cardiol. 2013; 101(Suppl 2):176-82. 